\title{
Palladium - Doped ZnO Thin Film Hydrogen Gas Sensor
}

\author{
Q. G. Al-zaidi (Corresponding author) \\ Physics Department, College of Science, University of Baghdad, Baghdad, Iraq \\ Tel: 964-770-298-1421 E-mail: qahtaniliya@yahoo.co.uk
}

Abdulla. M. Suhail

Associate Professor Physics Department, College of Science, University of Baghdad, Baghdad, Iraq

Tel: 964-770-871-0350 E-mail: Abdulla_shl@yahoo.com

\author{
Wasan R. Al-azawi \\ Assistant Professor, Physics Department, College of Science, University of Baghdad, Baghdad, Iraq \\ Tel: 964-770-539-6446 E-mail: wasan_alazawi@yahoo.com
}

Received: December 3, 2010 Accepted: December 28, 2010 doi:10.5539/apr.v3n1p89

\begin{abstract}
Palladium - doped $\mathrm{ZnO}$ thin film was deposited by chemical spray pyrolysis on glass substrate to be a fast hydrogen gas sensor. The prepared $\mathrm{ZnO}$ films were doped by dipping in palladium chloride $\mathrm{PdCl}_{2}$ dissolved in ethanol $\mathrm{C}_{2} \mathrm{H}_{5} \mathrm{OH}$. The optical properties and the surface morphology of the prepared films were studied. The sensitivity and response time behaviors of the $\mathrm{ZnO}$ - based gas sensor to hydrogen gas were investigated. The film sensitivity dependence on the temperature and test gas concentration were tested and the optimum operation temperature was determined at around $280{ }^{\circ} \mathrm{C}$. The response time of $2-3 \mathrm{~s}$ of the doped $\mathrm{ZnO}$ film was highly improved compared to the slow response of few minutes of the traditional $\mathrm{ZnO}$ hydrogen gas sensors.
\end{abstract}

Keywords: $\mathrm{SMO} \mathrm{ZnO}$ films, Spray pyrolysis, $\mathrm{H}_{2}$ gas sensor, Palladium catalyst, Response time

\section{Introduction}

Hydrogen $\left(\mathrm{H}_{2}\right)$ is expected to supplant hydrocarbons and becomes "the common fuel of the future". Hydrogen is an invisible, odorless, and flammable gas. It has a wide range of flammability in air, which is about $4-75 \%$ by volume and the lowest limit of $\mathrm{H}_{2}$ in air to cause explosion is $5 \%$ as mentioned by Schlager and Weisblatt (2006). This makes it more flammable than other fuels usually used. Therefore, there is a need for a devise capable of detecting the low levels of this gas ranging from 0.1-100 ppm as reported by Liu et al (2001) and Xu et al (2008).

The traditional hydrogen sensors based on semiconductor metal oxide material. This is due to the change of their properties when they interact with the hydrogen. Among the semiconductor metal oxide - based hydrogen sensors are tungsten oxide Abdul Halim (2008), tin oxide Mitra and Mondal (2008), and zinc oxide Patrícia et al (2001). The $\mathrm{ZnO}$ nanostructure is considered as a promising chemical gas sensitive material. This is mainly attributed to the large chemically - sensitive surface to volume ratio requested for high - sensitivity gas sensing as advised by Patrícia et al (2001), Francia et al (2008). The ability of these semiconductor oxides to transfer the gas concentration to a change in the electric resistance allows the using of the traditional simple techniques for implantation the final product.

The sensitivity of the nanostructure $\mathrm{ZnO}$ material for many chemical gases has been reported by different preparation techniques such as chemical vapor deposition (CVD) Schadow (2005), DC and RF sputtering Min (2003) and Suchea et al (2006), sol-gel Bahadur (2004), and the oxidation of the original material Abhijith (2006). The dominant behavior of all the mentioned gas sensors is the slow response time, which sometimes reaches several minutes.

In this work, we report on palladium doped $\mathrm{ZnO}$ nanostructure film gas sensor fabricated using chemical spray pyrolysis deposition technique. The palladium doped $\mathrm{ZnO}$ shows a relatively fast response $\mathrm{H}_{2}$ gas sensor compared with undoped samples. 


\section{Experimental}

\subsection{Thin film Deposition}

The chemical techniques for the preparation of thin films have been studied extensively because such processes facilitate the designing of materials on a molecular level. The chemical spray pyrolysis is one of the chemical techniques applied to form a variety of thin films, resulting in good productivity from an uncomplicated apparatus. In the current research, zinc oxide thin films were deposited on glass substrates employing spray pyrolysis deposition chamber whose main components set up is illustrated in the schematic diagram of Fig. 1. It is essentially made up of a precursor solution, carrier gas assembly connected to a spray nozzle, and a temperature - controlled hot plate heater.

A $0.1 \mathrm{M}$ concentration aqueous precursor solution of zinc chloride $\mathrm{ZnCl}_{2}$ has been prepared by dissolving a solute quantity of $1.36 \mathrm{~g}$ of $\mathrm{ZnCl}_{2}$ in $100 \mathrm{~mL}$ distilled water (the solvent). A magnetic stirrer is incorporated for this purpose for about $10-15$ minutes. Prior to depositing the films, the glass substrates were thoroughly cleaned in distilled water and dried in air for five minutes. After that, they were soaked in alcohol to remove any stains and contaminants. The substrate temperature was maintained within $450 \pm 5{ }^{\circ} \mathrm{C}$ during the deposition period. The film thickness was controlled by both the precursor concentration and the number of sprays, or alternatively, spraying time. Thus, a 4 - second spraying time is maintained during the experiment with specific nitrogen carrier gas pressure. The spray rate of solution was maintained at $5.3 \mathrm{~mL} \mathrm{min.} .^{-1}$ throughout the experiment.

The possible chemical reaction that takes place on the heated substrate to produce $\mathrm{ZnO}$ thin film may be described by the following reaction:

$$
\mathrm{ZnCl}_{2}+\mathrm{H}_{2} \mathrm{O}-\mathrm{ZnON}+2 \mathrm{HCl} \uparrow
$$

The precipitated $\mathrm{ZnO}$ on the glass substrate was in the form of nanocrystals which is clearly identified by the AFM morphology study of the $\mathrm{ZnO}$ nanofilms.

\subsection{Surface sensitization by palladium}

Metal oxide gas sensors need a catalyst deposited on the surface of the film to accelerate the reaction, increase the sensitivity, and to improve the response time of the detector Abhijith (2006). Small amounts of noble metal additives, such as Pd or Pt are commonly dispersed on the semiconductor as activators or sensitizers to improve the gas selectivity, sensitivity and to lower the operating temperature as Patrícia et al (2001) pointed out.

For the above reasons, the surface of the deposited $\mathrm{ZnO}$ thin films were catalyzed using successive multiple dipping of the prepared samples in a $50 \mathrm{~cm}^{3}$ solution made up of dissolving $1 \%$ by weight palladium chloride $\mathrm{PdCl}_{2}$ in ethyl alcohol $\mathrm{C}_{2} \mathrm{H}_{5} \mathrm{OH}$. Each sample was successively dipped 20 times for about 2-3 s. After each dipping, the sample was heated to $30{ }^{\circ} \mathrm{C}$ in evacuated oven for 2 minutes to facilitate the evaporation of the volatile ethyl alcohol. Finally, the dipped samples were heat - treated at $230{ }^{\circ} \mathrm{C}$ for one hour in an evacuated oven.

\subsection{Al interdigitated elecrtodes}

An eight - finger metal mask was used to thermally evaporate the aluminum interdigitated electrodes on the doped $\mathrm{ZnO}$ samples. Both the spacing between the mask fingers and their width were equal to $1 \mathrm{~mm}$. This design has proven to be reliable throughout our work.

\subsection{Gas sensor testing system}

The fabricated gas sensor set up is illustrated in Fig. 2. The unit consists of a vacuum - tight stainless steel cylindrical test chamber of diameter $163 \mathrm{~mm}$ and of height $200 \mathrm{~mm}$ with the bottom base made removable and of $\mathrm{O}$ - ring sealed. The effective volume of the chamber is $4173.49 \mathrm{cc}$; it has an inlet for allowing the test gas to flow in and an air admittance valve to allow atmospheric air after evacuation. Another third port is provided for vacuum gauge connection.

A multi-pin feed through at the base of the chamber allows for the electrical connections to be established between the sensor and the heater assembly. The heater assembly consists of a hot plate and a thermocouple inside the chamber in order to control the operating temperature of the sensor. The PC - interfaced multi meter was used to register the variation of the sensor resistance exposed to predetermined hydrogen gas concentration. The chamber can be evacuated using a rotary pump to a rough vacuum of $2 \times 10^{-\mathbf{s}}$ mber. A gas mixing manifold was incorporated to control the mixing ratios of the test and carrier gases prior to being injected into the test chamber. The mixing gas manifold is fed by zero air and test gas through a flow meter and needle valve 
arrangement. This arrangement of mixing scheme was done to ensure that the gas mixture entering the test chamber is premixed thereby giving the real sensitivity.

\section{Results and discussion}

\subsection{Structure and optical properties}

The structure and lattice parameters of ZnO films were analyzed by a LabX XRD 6000 SHIMADZU XR Diffractometer with $\mathrm{Cu} \mathrm{K} \alpha$ radiation of (voltage $30 \mathrm{kV}$, current $15 \mathrm{~mA}$, scanning speed $=4 \% \mathrm{~min}$ ), as illustrated in Fig. 3 and the effect of the Pd dopant on the structure of the film can be shown in Fig. 4. Diffraction pattern was obtained with $29^{\circ}$ starting from $20^{\circ}$ to $50^{\circ}$ at $6^{\circ}$ glancing angle. In both the as - deposited and $\mathrm{Pd}$ - doped $\mathrm{ZnO}$ thin films, the $\mathrm{X}$ - ray diffraction spectra possess one sharp and three small peaks. It meant that the film is polycrystalline with crystal planes (100), (002), (101) and (102). The film is crystallized in the wurtzite phase and presents a preferential orientation along the c-axis indicated by the plane (002). The result is in a good agreement with data mentioned in the literature (JCPDF card no 36-1451). The strongest peak observed at $=$ $34.3646^{\circ}(\mathrm{d}=0.260 \mathrm{~nm})$ can be attributed to the (002) plane of the hexagonal $\mathrm{ZnO}$. The (100), (101) and (102) peaks were also observed at $=31.7013^{\circ}, 36.1732^{\circ}$ and $47.4424^{\circ}$, respectively but these peaks are of much lower intensity than the (002) peak. The c-axis lattice constant of the $\mathrm{ZnO}$ thin film was calculated from XRD data as $5.20 \mathrm{~nm}$. This value is not far away from one mentioned by Gumu et al (2006).

The morphology of the $\mathrm{ZnO}$ sensing film surface was imaged by atomic force microscope (AFM) model AA3000 SPM from Angstrom Advanced Inc. and is illustrated in Fig. 5. The Figure shows the formation of the nanostructure. The root mean square of the surface roughness prepared by this method was of order of $50 \mathrm{~nm}$. This is an indication of smoothness of the pyrolysed $\mathrm{ZnO}$ films Moses et al (2007). The surface roughness may be attributed to the clustering of the grains in the film prepared under high ambient pressure Islam and Podder (2009). The overall conduction in a sensor element is determined by the surface reactions, the resulting charge transfer processes with the underlying semiconducting material, and the transport mechanism within the sensing layer. This is considered to be an important factor in the application of the $\mathrm{ZnO}$ film to be a gas sensor Barsan and Weimar (2001).

The optical properties of $\mathrm{ZnO}$ films were carried out with a double beam spectrophotometer (Perkin Elmer Lambda 2S) in the UV/VIS/NIR regions. The optical transmittance at normal incidence was recorded in the wavelength range of 300-1100 nm. The sprayed films were transparent in the visible with a sharp UV cut - off at $390 \mathrm{~nm}$. The transmittance was about $85 \%$ which can be greatly improved by reducing the film thickness. The absorption spectra of $\mathrm{ZnO}$ film sprayed at $450^{\circ} \mathrm{C}$ before and after palladium sensitization are illustrated in Figs. 6 and 7 respectively. The films with higher absorption provide higher photocurrent, since the higher the number of absorbed photons is, the larger the photocurrent. The wavelengths at maximum absorption were found to be at UV band.

The extrapolating of the linear part of the plot $(\alpha h v)^{2}$ versus the photon energy $h v^{2}$ to $(\alpha h v)^{2}=0$ gives rise to estimate the energy gap value $\mathrm{E}_{\mathrm{g}}$ of the $\mathrm{ZnO}$ material. The $\mathrm{E}_{\mathrm{g}}$ value was found to be $3.2 \mathrm{eV}$. This energy gap is comparable to the accepted value $(\sim 3.3 \mathrm{sV})$ of the energy gap of $\mathrm{ZnO}$ reported recently Gumu et al (2006).

\subsection{Response to hydrogen gas}

The experimental arrangement for sensitivity measurement is shown in Fig. 2. The sensor is mounted on a hot plate heater housed in a closed chamber. A $220 \mathrm{~V}$ a.c. power was applied to the heater and temperature was measured using chromel -alumel thermocouple and precision digital temperature controller (GEMO109). The hydrogen gas was passed through gas flow meter and by adjusting the flow rate of gas using needle valve, the concentration of hydrogen in the test chamber could be changed. The conductance of the sensor was measured with digital PC - interfaced multimeter (UNI-T81A-B). The change in sensor temperature $T$, and conductance $\mathrm{S}$, were simultaneously measured.

The gas response of the resistive sensor $\mathrm{S}$ is defined by the ratio of the film resistance in test gas to its resistance in air. The response of the sensor is affected by the geometrical factor $\mathrm{K}$, the electronic characteristics term $\left(e_{g} / 6 m_{\mathrm{g}}\right)$ of the sensing element and the adsorption induced band bending term $\left(\mathrm{V}_{\mathrm{ga}}^{1 / 2}-\mathrm{W}_{\mathrm{gI}}^{1 / 2}\right)$ as in the following relation, Chen et al (2008):

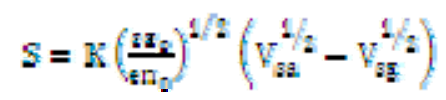

where $K=4 / D_{\lambda}$ ( $D_{\lambda}$ is the Debye length of sensing material) and $n_{o}$ is the carrier concentration in air. $V_{s a}$ and $V_{s g}$ are the adsorbance-induced band bending potential in air and in $\mathrm{H}_{2}$ gas, respectively. Enhancement of the sensor sensitivity to $\mathrm{H}_{2}$ gas can be accomplished by controlling the above three terms via doping, modulating the 
operating temperature, or by altering the geometric parameters. In our work, sample doping with palladium highly increased the adsorption of hydrogen gas on the $\mathrm{ZnO}$ surface, and thus modulating the surface depletion region thickness through the variation of the charge carrier concentration.

Fig. 8 shows the dependence plot of conductance vs. operating time for two successive test gas pulses $\left(5 \% \mathrm{H}_{2}\right.$ mixed with $95 \%$ atmospheric air) at $200{ }^{\circ} \mathrm{C}$ temperature and bias voltage of 10 volts. The $\mathrm{Pd}-$ doped $\mathrm{ZnO}$ thin film exhibited a comparatively very fast response time to conductance change when subjected to $5 \%$ hydrogen mixed with 95\% atmospheric air Abhijith (2006). Thus, a rise time of about $3 \mathrm{~s}$ and a slow recovery time of 5 minutes were observed. Since fast response to the flammable hydrogen leak below the gas explosion limit $(\sim 4 \%)$ is extremely crucial, the above sensor response may be accepted for this purpose. The sensitivity $\mathrm{S}$ as a function of the hydrogen gas concentration $\mathrm{C}$ is illustrated in Fig. 9. The Figure displays that the sensitivity of the sensor is linear in the low gas concentration region, whereas it is a power relation in the high gas concentration $\mathrm{Xu}(2008)$.

\subsection{Operation parameters of the sensors}

One of the most important disadvantages of $\mathrm{ZnO}$ gas sensors is the high temperature required for the sensor operation $\left(200-500^{\circ} \mathrm{C}\right)$. For that reason, the effect of the operation temperature on the thin films sensitivity was studied with the aim of optimizing the operation temperature to the lowest possible value.

The gas sensitivity tests performed at room temperature show no variation on the film conductivity, even with the increase of the gas concentration. The increase in the operation temperature leads to an enhancement of the films sensitivity. In Fig. 10 we depict the dependence of maximum conductance on the temperature used. The best operating temperature for hydrogen sensor based on $\mathrm{Pd}-$ doped $\mathrm{ZnO}$ thin film is around $280{ }^{\circ} \mathrm{C}$. It can be noticed from the figure that the $\mathrm{ZnO}$ film shows a negative temperature coefficient of resistance up to $270{ }^{\circ} \mathrm{C}$, whereas above $285^{\circ} \mathrm{C}$ it shows a positive temperature coefficient.

\section{Conclusions}

The structure, surface morphology, and sensing properties of $\mathrm{ZnO}$ films as a $\mathrm{H}_{2}$ gas sensor obtained by spray pyrolysis system were investigated.

The XRD structural characteristics revealed that the film obtained using this technique was polycrystalline crystallized in the wurtzite phase. Furthermore, the morphology image demonstrated that the films were uniform and consisting from grain size nanocrystal.

The sensitivity as well as the response time were greatly improved by doping the as - deposited films with palladium noble metal using multiple dippings and increasing the operation temperature. The maximum sensitivity in this study was obtained due to the catalytic effect of the $\mathrm{Pd}$ - dipped $\mathrm{ZnO}$ film at the operation temperature of $280^{\circ} \mathrm{C}$ with a fast responsive time of about $3 \mathrm{~s}$.

The variation of the operating temperature of the film led to a significant change in the sensitivity of the sensor with an ideal operating temperature dependence of the gas used.

\section{References}

Abhijith, N. (2006). Semiconducting Metal Oxide Gas Sensors: Development and Related Instrumentation. M. Sc. Thesis, Indian Institute of Science.

Bahadur, Harish. (2004). Characterization of ZnO Thin Films. Proc. $18^{\text {th }}$ European Frequency and Time Forum, Univ. Surrey, Guildford, UK, Institute of Electrical Engineers (IEE) Vol. 18.

Barsan, N. and Weimar, U. (2001). Conduction Model of Metal Oxide Gas Sensors, Journal of Electroceramics, 7, 143-167.

Chen, Po - Chiang, Shen, Guozhen, and Zhou, Chongwu. (2008). Chemical Sensors and Electronic Noses Based on 1-D Metal Oxide Nanostructures. IEEE Trans. Nanotechnol, 7 (6) 668-682.

Francia, Girolamo Di, and Alfano, Brigida. (2008). Vera La Ferrara,Conductometric Gas Nanosensors. ENEA CR-Portici P.le E. Fermi, 180055 Napoli, Italy.

Gumu, C., Ozkendir, O. M., Kavak, H., Ufuktepe, Y. (2006). Structural and optical properties of zinc oxide thin films prepared by spray pyrolysis method. Journal of Optoelectronics and Advanced Materials, Vol. 8, No. 1, p. $299-303$.

Islam, M. R. and Podder, J. (2009). Optical properties of $\mathrm{ZnO}$ nano fiber thin films grown by spray pyrolysis of zinc acetate precursor. Cryst. Res. Technol, 44, No. 3, 286 - 292. 
Lin, Jenshan. (2008). Integration and Testing of Low Power Wireless Hydrogen Sensor Modules. NAG3-2930 Final Report for Sensors.

Liu, Wen - Chau, Chen, Huey - Ing, and Pan, Hsi Jen. (2001). Hydrogen Sensor. US patent, patent No. US 6, 293, 137.

Min, Yongki. (2003). Properties and Sensor Performance of Zinc Oxide Thin Films. Ph.D. thesis, Massachusetts Institute of Technology, September.

MITRA, P. and MONDAL, S. (2008). Hydrogen and LPG sensing properties of $\mathrm{SnO}_{2}$ films obtained by direct oxidation of SILAR deposited SnS. Bulletin of the Polish Academy of Science, technical science Vol. 56, No. 3.

Moses, A., Raj, Ezhil, Nehru, L.C., Jayachandran, M., and Sanjeeviraja, C. (2007). Spray pyrolysis deposition and characterization of highly (100) oriented magnesium oxide thin films. Cryst. Res. Technol, 42, No. 9, 867 875.

Patrícia, Nunes, Fortunato, Elvira, Martins, Rodrigo. (2001). Thin film combustible gas sensors based on Zinc Oxide. Mat. Res. Soc. Symp. Proc., Vol. 666.

Schadow, Klaus. (2005). MEMS/Nanotechnology Integration. Nanotechnology Aerospace Applications, pp. 8-1 $-8-2$.

Schlager, Neil and Weisblatt, Jayne. (2006). Alternative Energy. Volume 1-3, Michigan, USA, Thomson Gale.

Suchea, M., Christoulakis, S., Moschovis, K., Katsarakis, N., Kiriakidis, G. (2006). ZnO transparent thin films for gas sensor applications. Thin Solid Films, 515, 551-554.

$\mathrm{Xu}$, Tao. (2008). Ultra fast and ultra sensitive hydrogen sensors based on self-assembly monolayer promoted 2dimensional palladium nanoclusters. US patent No. 7,389,671 B1.

Yamazoe, Noboru and Shimanoe, Kengo. (2009). Receptor Function and Response of Semiconductor Gas Sensor. Journal of Sensors, Article ID 875704, 21 pages.

Zaini, Abdul Halim. (2008). Design of microhotplate based gas sensing system. M.Sc. thesis, May. 


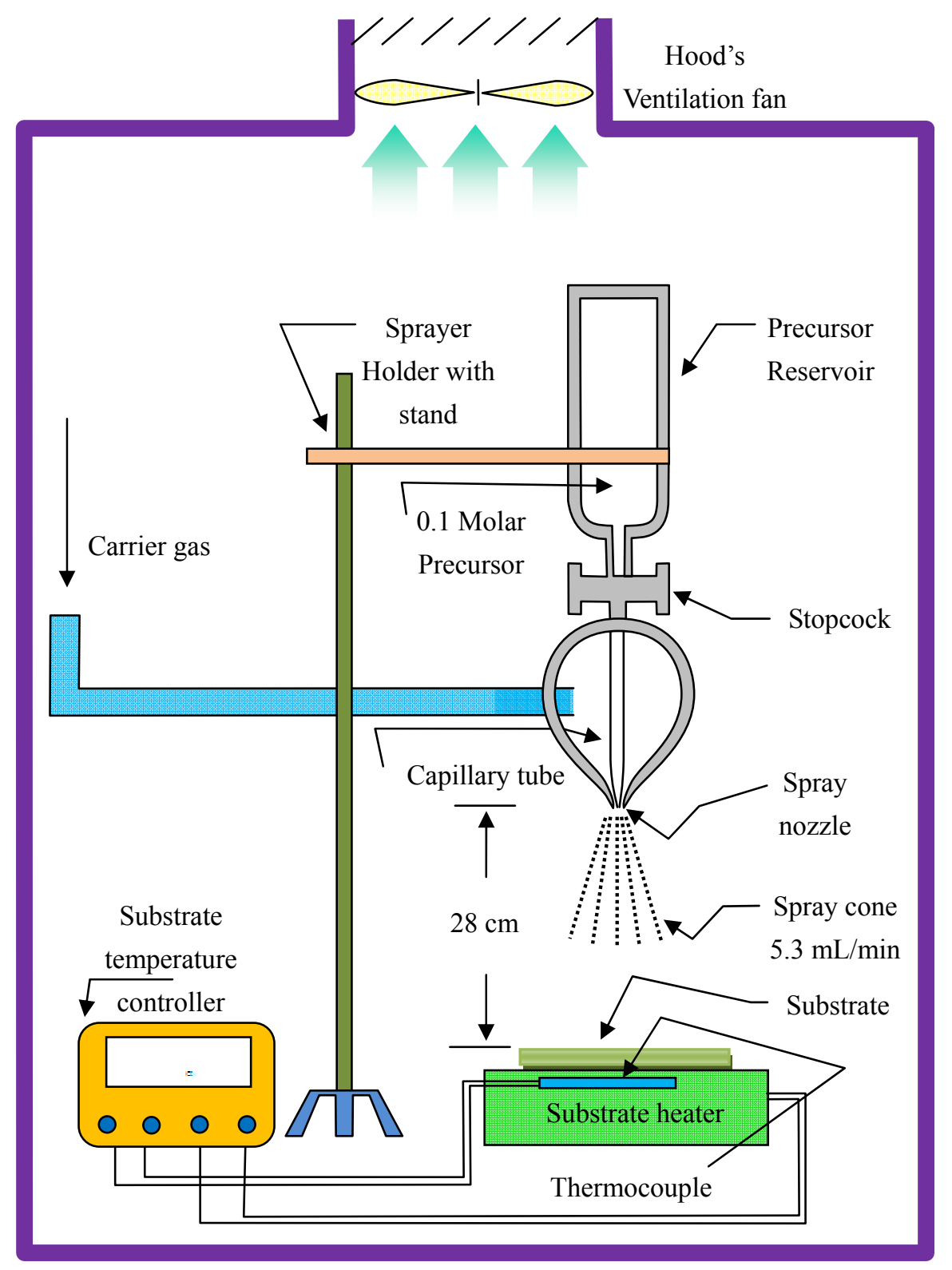

Figure 1. Experimental set up of the spray pyrolysis deposition technique 


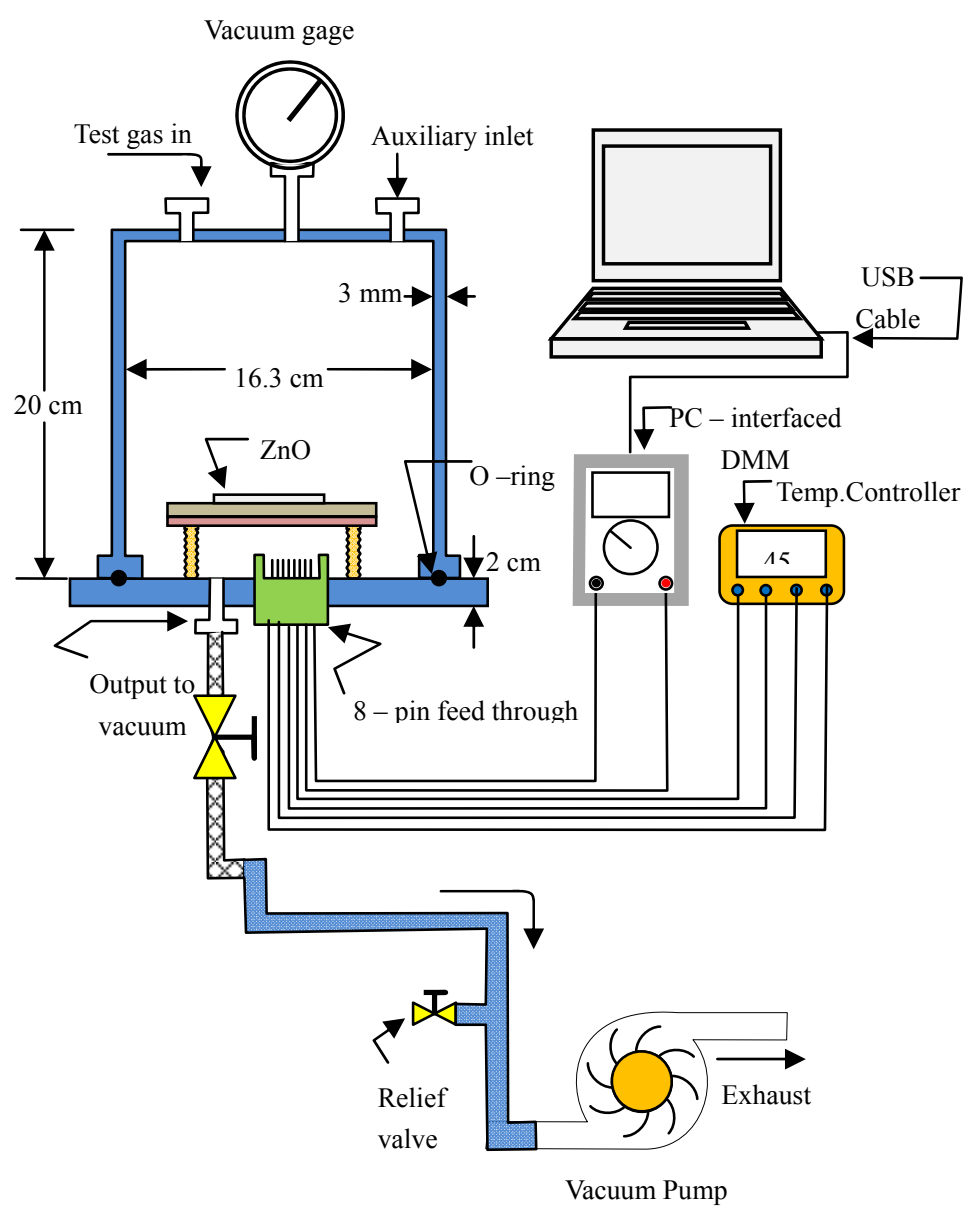

Figure 2. Sensor testing system 


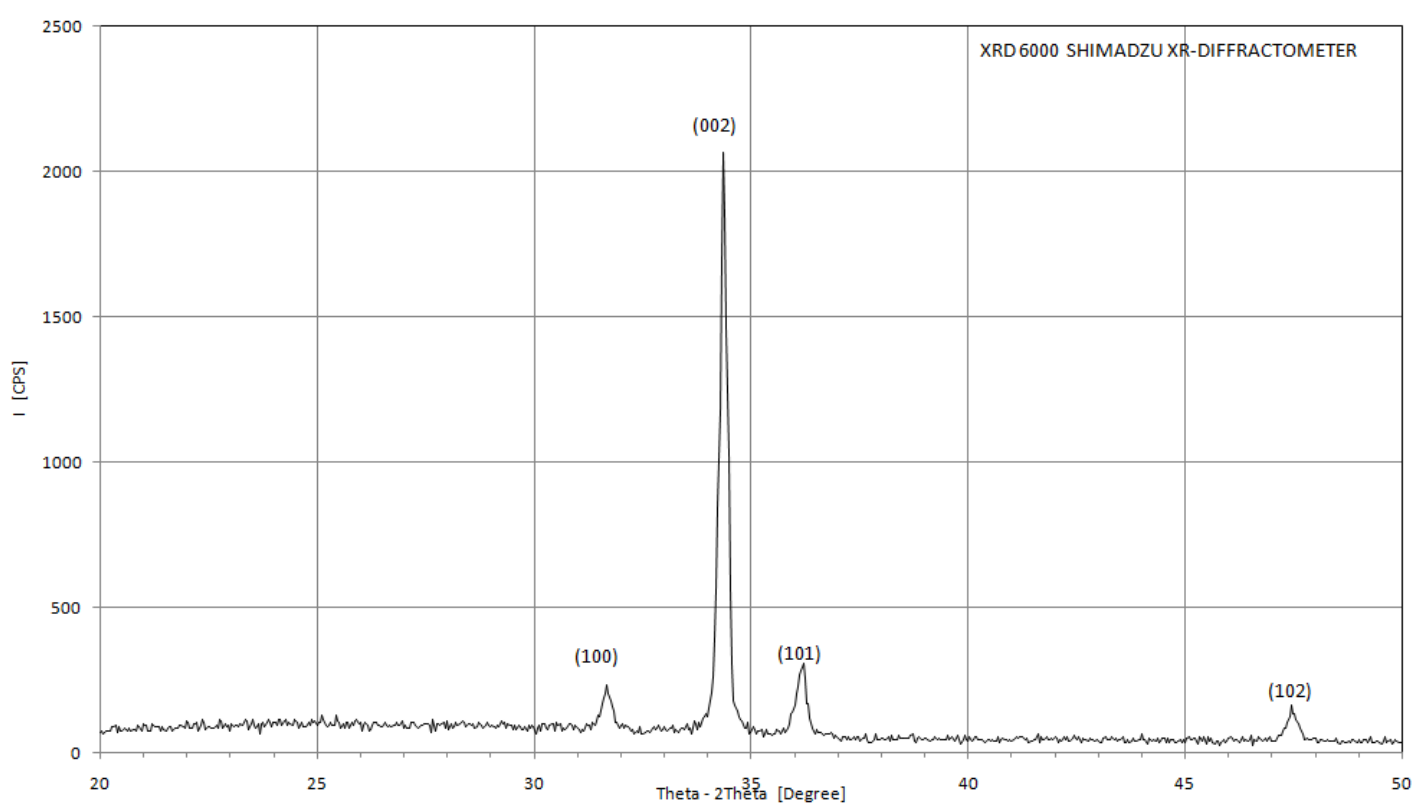

Figure 3. $\mathrm{XRD}$ of as - deposited $\mathrm{ZnO}$ thin film deposited on glass substrate at $450{ }^{\circ} \mathrm{C}$, film thickness is $1292.99 \mathrm{~nm}$

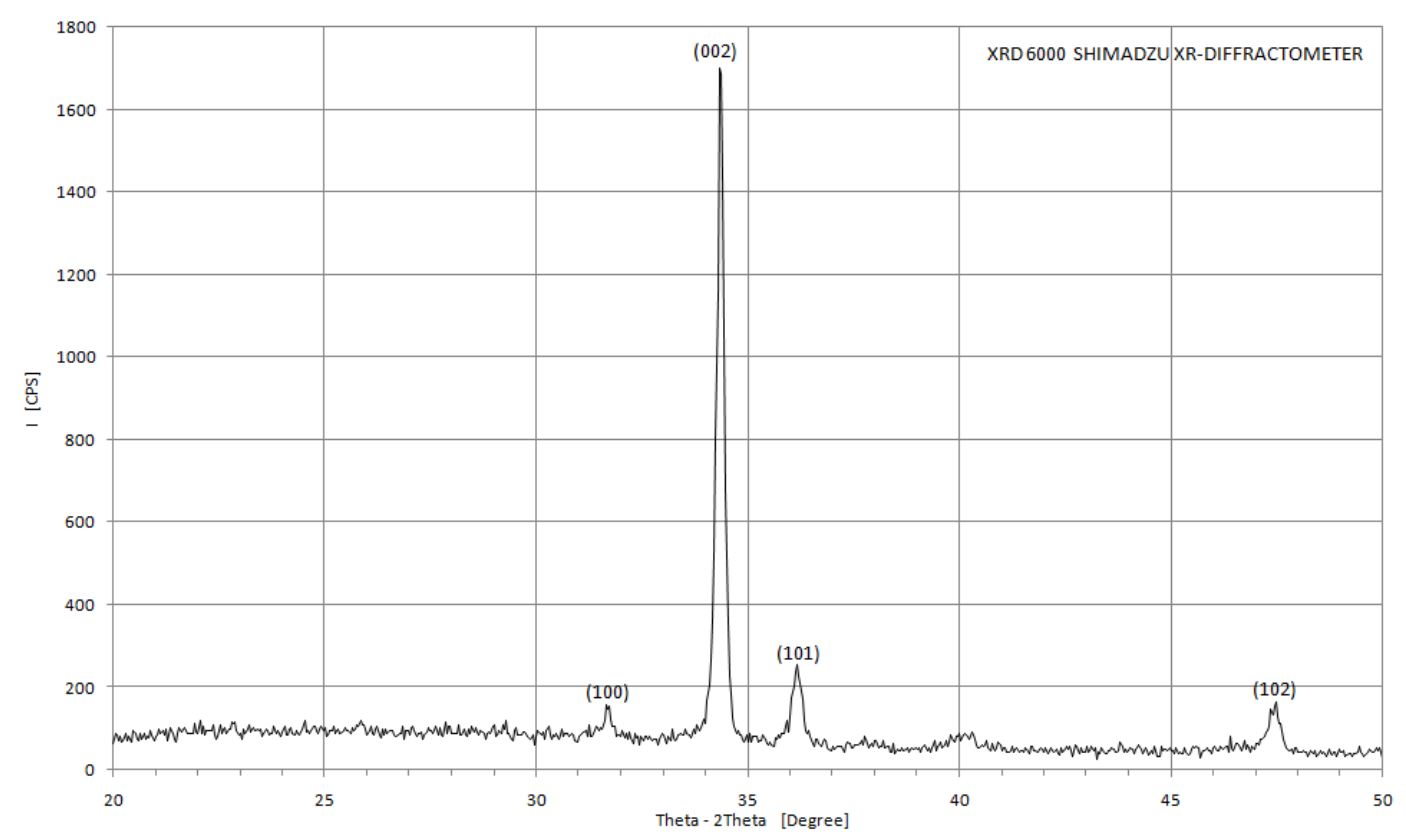

Figure 4. $\mathrm{XRD}$ of $\mathrm{PdCl} 2$ - sensitized $\mathrm{ZnO}$ thin film; film thickness is $976.342 \mathrm{~nm}$ 


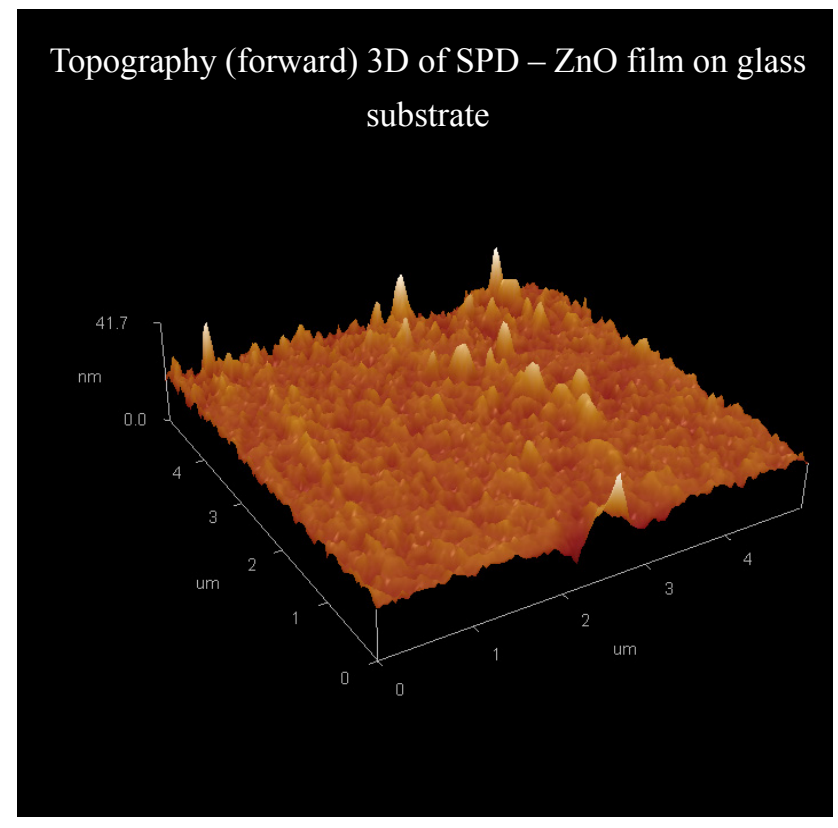

Figure 5. AFM image of $\mathrm{ZnO}$ film on glass substrate

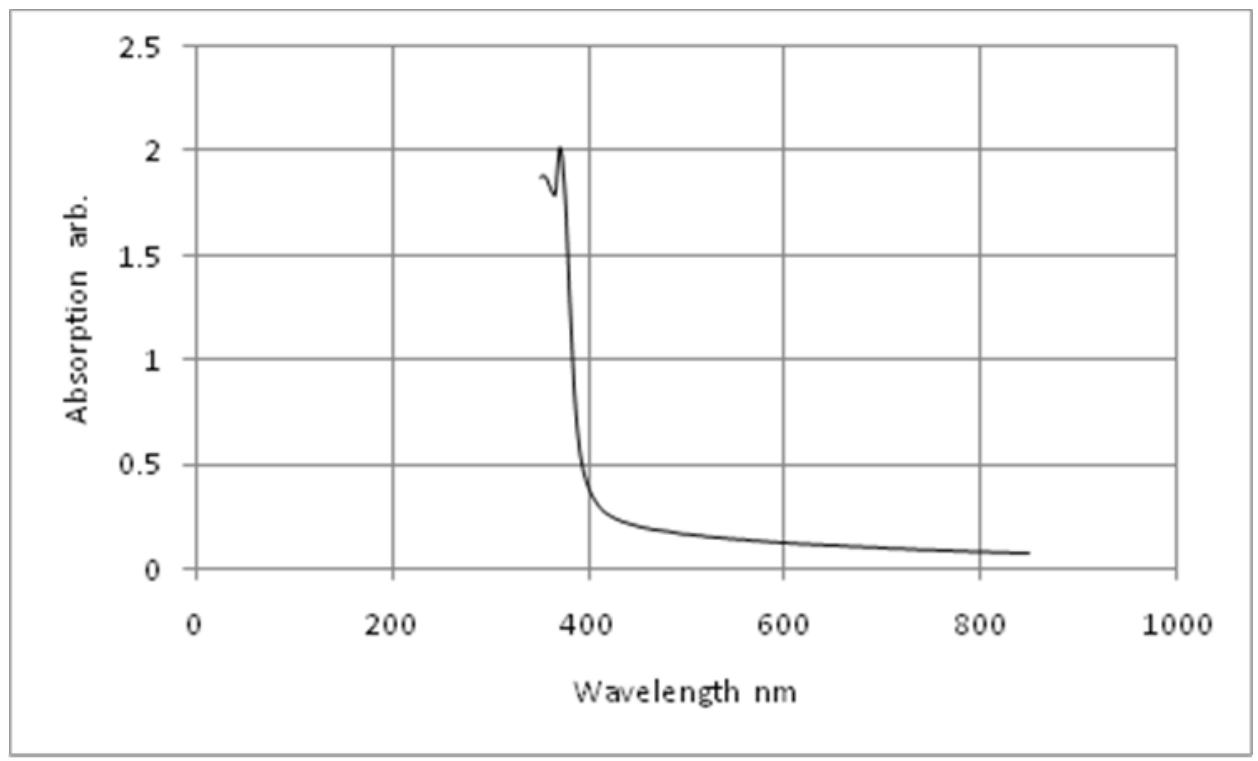

Figure 6. Absorption spectrum of as - deposited $\mathrm{ZnO}$ thin film sprayed on glass substrate at $450{ }^{\circ} \mathrm{C}$ 


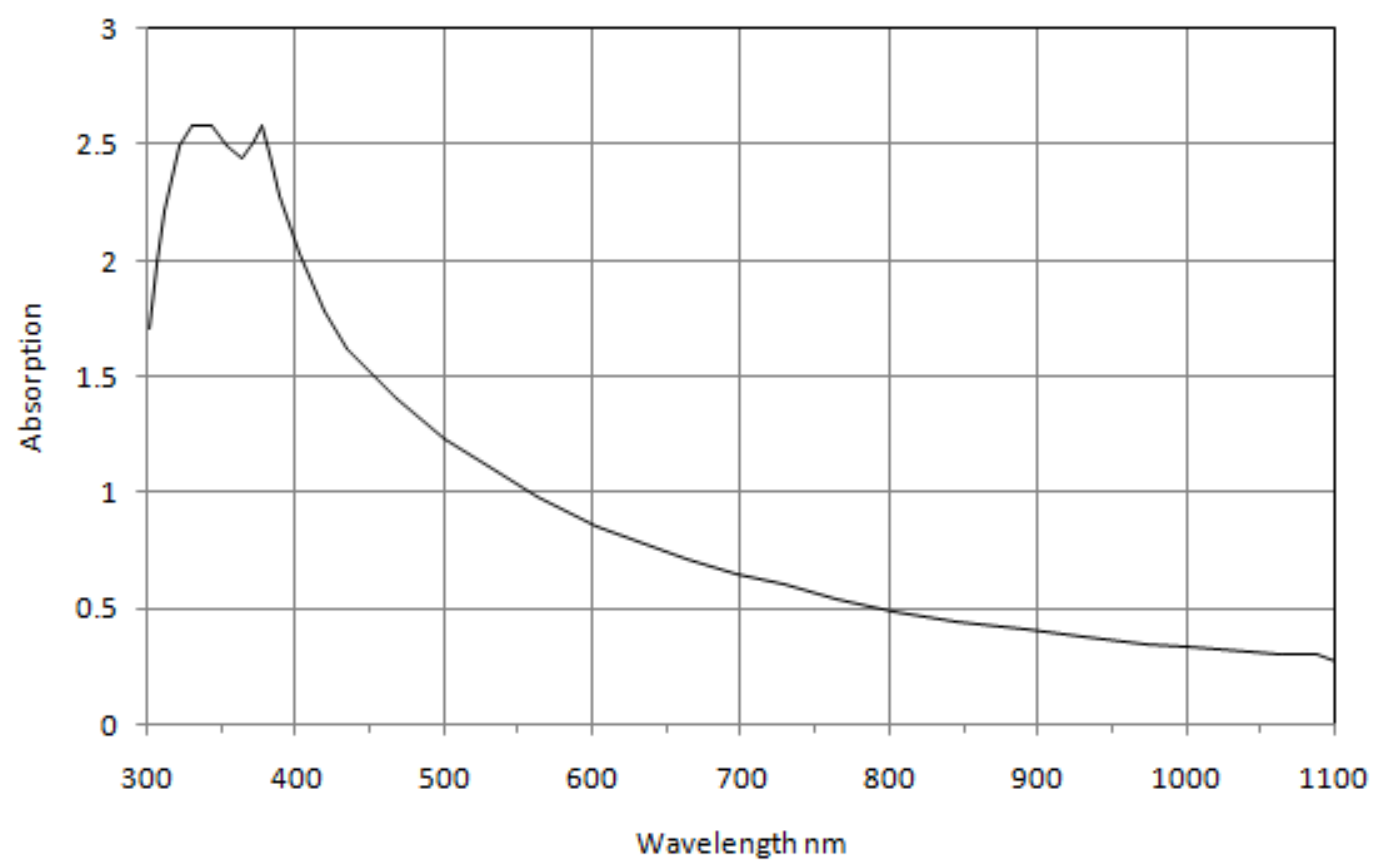

Figure 7. Absorption spectrum of $\mathrm{Pd}$ - sensitized $\mathrm{ZnO}$ thin film sprayed on glass substrate at $450{ }^{\circ} \mathrm{C}$

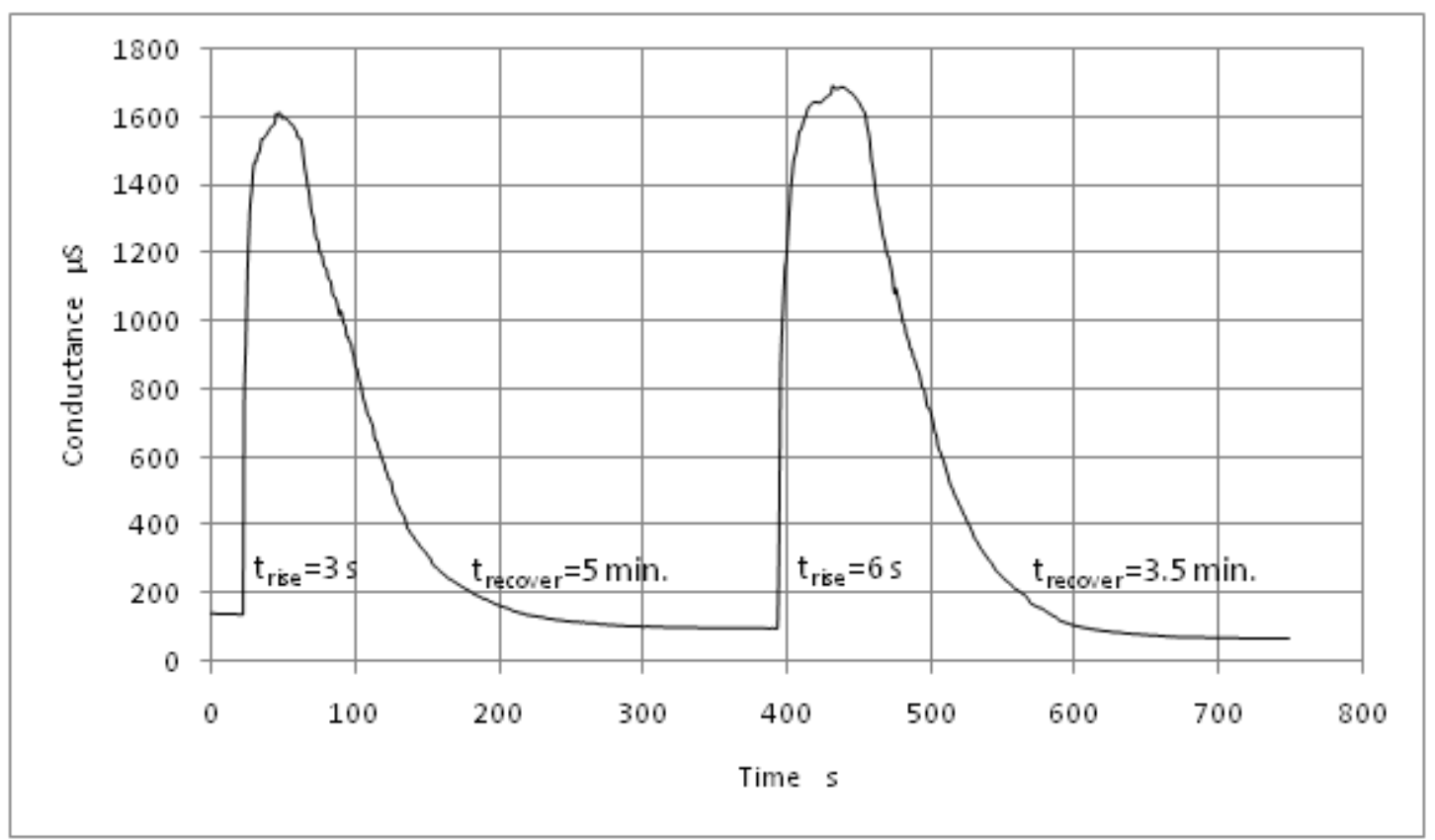

Figure 8. Sensing behavior of $\mathrm{Pd}-$ sensitized $\mathrm{ZnO}$ thin film to hydrogen test gas at $200{ }^{\circ} \mathrm{C}$ 


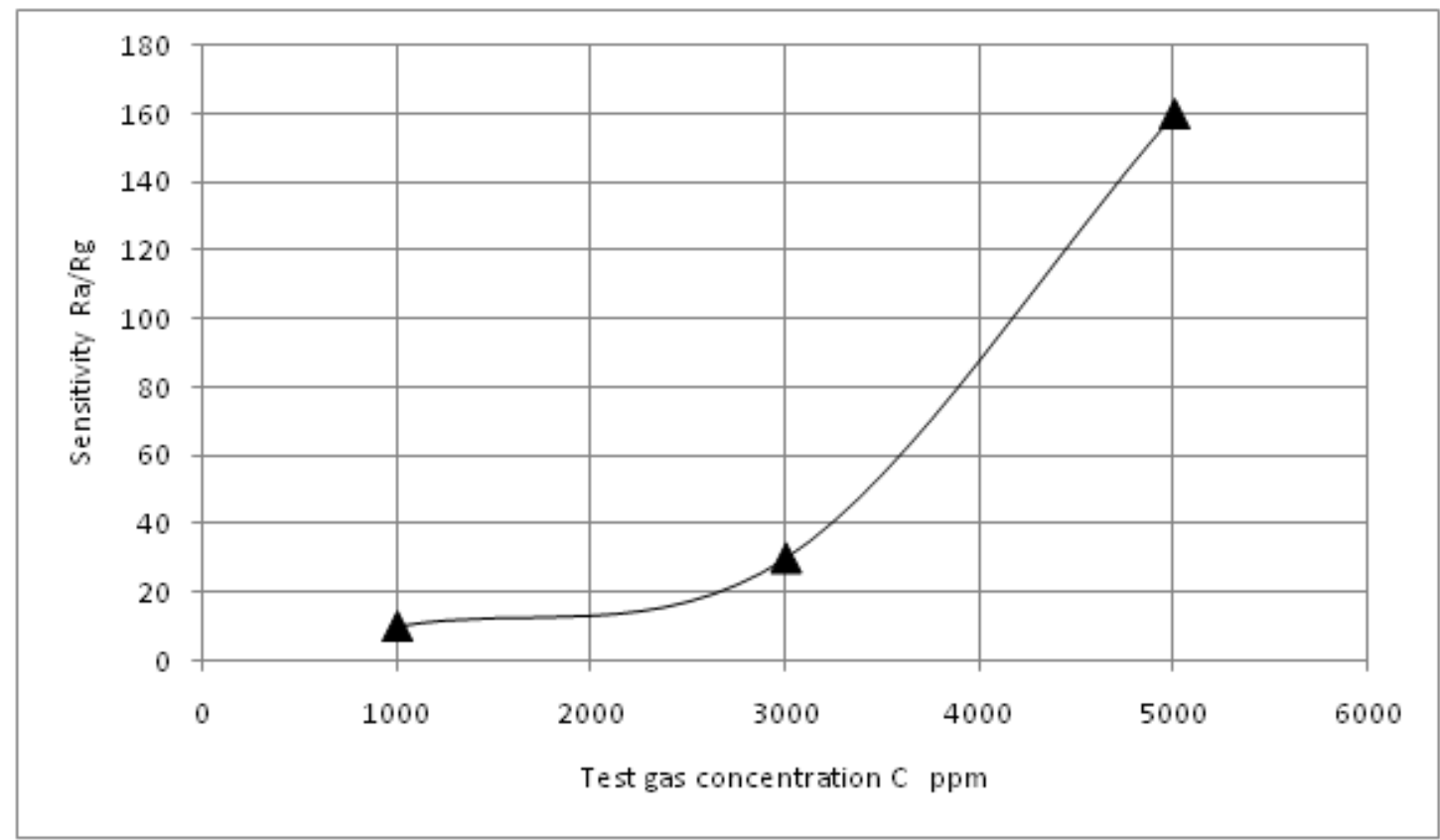

Figure 9. Dependence of sensor sensitivity on test gas concentration in ppm

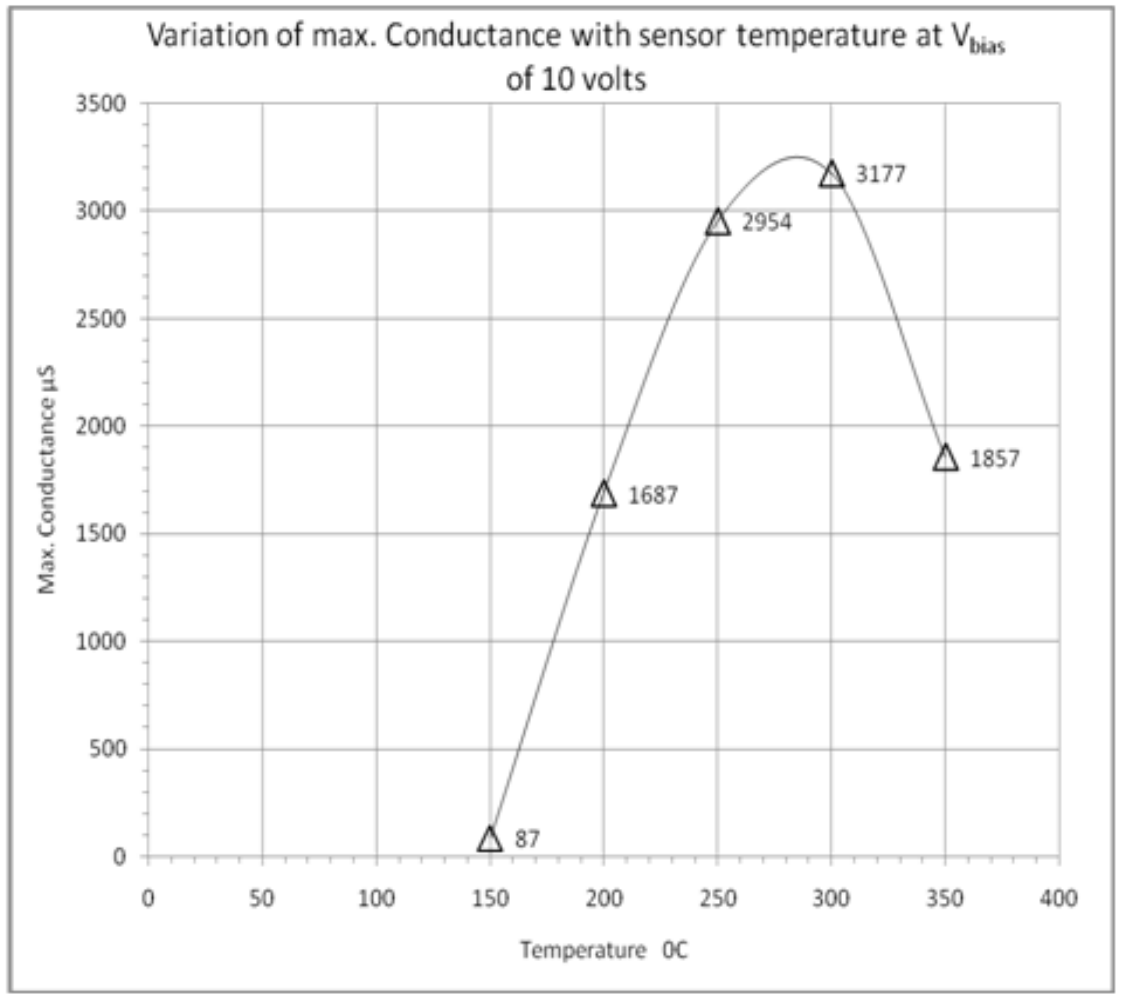

Figure 10. Variation of maximum conductance with sensor temperature at $\mathrm{V}_{\mathrm{bbs}}$ of 10 volts 